\title{
Effects of Triple $P$ parenting intervention on child health outcomes for childhood asthma and eczema: Randomised controlled trial
}

\author{
Alina Morawska ${ }^{\mathrm{a}}$, BA, BSc(Hons), MPH, PhD \\ Amy E. Mitchell ${ }^{\mathrm{a}}$, BSc, BNursing, GradCert, $\mathrm{PhD}$ \\ Scott Burgess ${ }^{\mathrm{c}}$, MBBS, PhD \\ Jennifer Fraser ${ }^{\mathrm{b}}, \mathrm{PhD}$
}

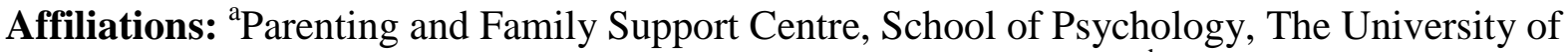
Queensland, Brisbane 4072, Australia, Email: alina@ psy.uq.edu.au; ${ }^{\mathrm{b}}$ Sydney Nursing School, The University of Sydney, Sydney NSW 2006, Australia, Email: jfraser@sydney.edu.au; and 'Lady Cilento Children's Hospital, 501 Stanley Street, South Brisbane QLD 4101, Australia, Email: scott@qclass.com.au.
\end{abstract}

Address correspondence to: Alina Morawska, Parenting and Family Support Centre, School of Psychology, The University of Queenstand, Brisbane QLD 4072, Australia. Ph: +61 7 3365 7304. Fax: +61 73365 6724. Email: alina@psy.uq.edu.au

Short title: Effects of parenting intervention on child health outcomes

Funding: This research was supported by the Australian Research Council DP110102449. The funder had no role in any aspect of the study design; data collection, analysis, or interpretation; or drafting or submitting this article for publication.

\section{Conflict of Interest and Financial Disclosure Statement:}

The Triple P - Positive Parenting Program is owned by The University of Queensland. The University, through its main technology transfer company, UniQuest Pty Ltd, has licensed Triple P International Pty Ltd to publish and disseminate the program worldwide. Royalties stemming from published Triple $\mathrm{P}$ resources are distributed in accordance with the University's intellectual property policy and flow to the Parenting and Family Support Centre, School of Psychology, Faculty of Health and Behavioural Sciences, and contributory authors. No author has any share or ownership in Triple P International Pty Ltd. Alina Morawska is an author of various Triple $\mathrm{P}$ resources including that reported in this study. Amy Mitchell is a staff member employed at the Parenting and Family Support Centre. The other authors have no potential conflicts of interest or financial relationships relevant to this article to disclose.

Australia New Zealand Clinical Trials Registration: ACTRN12611000558921 


\section{Highlights}

- Educational and family-based interventions have had limited effects on child health outcomes or adherence. Parenting interventions are effective for reducing child behavioural and emotional problems, but have generally not been evaluated in child illness contexts.

- Brief, group intervention led to fewer child illness behaviour problems, improved parental self-efficacy and better parent and family health related quality of life HRQL, and improved child health.

- The study demonstrates that improved parenting can lead to better child health outcomes.

- Parents' needs for parenting and child behaviour support should be routinely assessed by clinicians. Parenting intervention should be considered as an element of chronic health condition management to improve child health outcomes.

\section{Keywords:}

Parenting, behavioural family intervention, asthma, eczema, atopic dermatitis, chronic disease, child, self-efficacy, child behaviour, health behaviour 


\begin{abstract}
Childhood chronic health conditions have considerable impact on children. We aimed to test the efficacy of a brief, group-based parenting intervention for improving illness-related child behaviour problems, parents' self-efficacy, quality of life, parents' competence with treatment, and symptom severity. A 2 (intervention vs. care as usual) by 3 (baseline, postintervention, 6-month follow-up) design was used, with random group assignment. Participants were 107 parents of 2- to 10-year-old children with asthma and/or eczema. Parents completed self-report questionnaires, symptom diaries, and home observations were completed. The intervention comprised two 2-hour group discussions based on Triple P. Parents in the intervention group reported (i) fewer eczema-related, but not asthma-related, child behaviour problems; (ii) improved self-efficacy for managing eczema, but not asthma; (iii) better quality of life for parent and family, but not child; (iv) no change in parental treatment competence; (v) reduced symptom severity, particularly for children prescribed corticosteroid-based treatments. Results demonstrate the potential for brief parenting interventions to improve childhood chronic illness management, child health outcomes, and family wellbeing. Effects were stronger for eczema-specific outcomes compared to asthmaspecific outcomes. Effects on symptom severity are very promising, and further research examining effects on objective disease severity and treatment adherence is warranted.
\end{abstract}




\section{Introduction}

Chronic child health conditions are common (Van Cleave, Gortmaker, \& Perrin, 2010) and children experience more behavioural, emotional and academic problems compared to healthy children (Pinquart, 2012; Pinquart \& Shen, 2011; Pinquart \& Teubert, 2012). The majority of conditions require daily management, yet non-adherence with treatment and prevention is around 50\% (Morton, Everard, \& Elphick, 2014).

Existing health care focuses largely on a medical education model which has shown limited success in improving adherence (Dean, Walters, \& Hall, 2010; Ersser et al., 2014) and family-based approaches have also shown limited effects (Eccleston, Palermo Tonya, Fisher, \& Law, 2012; Law, Fisher, Fales, Noel, \& Eccleston, 2014). The theoretical and empirical literatures provide compelling evidence that parenting plays a central role in children's health outcomes (Morawska, Calam, \& Fraser, 2015; Wood et al., 2008); yet, current approaches to childhood illness management do not target parenting (Law et al., 2014). Parent and family factors impact on illness onset (Mrazek et al., 1999), and disease course (Rohan et al., 2014), and parents of chronically ill children engage in different parenting practices compared to parents of healthy children (Holmbeck et al., 2002; Pinquart, 2013).

Parenting practices are readily modifiable and may serve as a pathway to better parenting and child outcomes, and potentially to better health outcomes (Morawska, Calam, et al., 2015). Behavioural parenting interventions are recognised as best practice in the treatment of parenting and child behaviour difficulties (O'Connell, Boat, \& Warner, 2009), however these have rarely been applied in the context of child illness management (Kirk et al., 2012). Recent studies have demonstrated some positive, albeit mixed, effects of parenting intervention for child chronic conditions (Clarke, Calam, Morawska, \& Sanders, 2014; 
Doherty, Calam, \& Sanders, 2013; Lohan, Morawska, \& Mitchell, 2015; Sassmann, de Hair, Danne, \& Lange, 2012; Westrupp, Northam, Lee, Scratch, \& Cameron, 2015) providing promising signs that this approach may add value to existing health services.

To date interventions for parents of children with chronic health conditions have focussed on a medical model, and the evaluation of psychosocial interventions has been limited. Those parenting interventions which have been evaluated have had mixed evidence, potentially because they have generally not tailored programs for children with chronic health conditions (Westrupp et al., 2015); used interventions with multiple sessions which are burdensome for parents to attend (Sassmann et al., 2012; Westrupp et al., 2015) \} or included only a small parenting component within a more complex intervention (Lohan et al., 2015). Thus, our aim was to test the efficacy of a brief, group parenting intervention for parents of children with asthma and/or eczema, on parents' confidence with illness management, child illness-related behaviour problems, quality of life, symptom severity and parent competence in relation to administering their child's treatment. Our focus was on asthma and eczema as these are the two most common childhood chronic health conditions in Australia, affecting $20 \%$ and $17 \%$ of Australian children respectively (Asher et al., 2006). Australian prevalence rates for asthma and eczema are comparable to those seen in the UK ( $21 \%$ and $16 \%$, respectively), and exceed those reported for most regions of North America (e.g., Canada, 18.2\%, 12\%), Europe (e.g., Germany, 13\%, 8\%), the Asia-Pacific (e.g., Hong Kong, 9\% and 5\%), and Africa (e.g., Nigeria, 6\% and 5\%) (Asher et al., 2006). We chose a heterogeneous illness group because these conditions commonly co-occur; there is limited evidence of a link between particular health conditions and specific behavioural and emotional problems, but rather a more general relationship between maladjustment and childhood chronic illness, and; practically it is easier for health services to deliver intervention to more heterogonous groups (Morawska, Calam, et al., 2015). We expected that participation in the parenting intervention would lead to: (i) 
fewer child illness-related behaviour problems; (ii) improved parental illness management self-efficacy; (iii) improved child, parent and family HRQL; (iv) better parental treatment competence; and (v) reduced symptom severity compared to care as usual.

This study is part of a larger trial, and general parenting and child behaviour, and parent and child adjustment outcomes, are reported separately (Morawska, Mitchell, Burgess, \& Fraser, 2015). This paper focuses specifically on health-related outcomes of illness management, symptom severity, and HRQL.

\section{Methods}

A 2 (Intervention vs. Care as Usual[CAU]) x 3 (time: pre-intervention[T1], postintervention[T2], 6-month follow-up[T3]) design was used. Permission was granted by relevant ethics review committees. Recruitment was across the Brisbane metropolitan region via school and healthcare settings. Study information to be distributed in school newsletters was emailed to all primary schools and child care centres within a $50 \mathrm{~km}$ radius of the city centre. Posters and brochures were sent to all family medical practices and paediatricians, dermatologists, and respiratory physicians in Brisbane, as well as the emergency departments and outpatients' clinics of Brisbane's two specialist children's hospitals.

Recruitment was from July 2011 to July 2013. Parents of 2- to 10-year-old children with asthma and/or eczema, with concerns about the child's behaviour, emotions, or illness management were eligible. Confirmation of diagnosis was obtained from the children's treating doctors. Families were ineligible if children had a disability or developmental disorder, or parents were receiving professional help for children's behaviour difficulties, or psychological help or counselling for themselves. Where both parents agreed to participate in the study, the parent who assumed primary responsibility for the child's health care was designated as the "primary" participant, and completed all study assessment. Secondary participants completed parent-report questionnaires only; these results are reported elsewhere 
(Morawska, Mitchell, et al., 2015). Where families had multiple children with asthma and/or eczema, parents selected one child to focus on for the purposes of the study.

\section{Procedure}

Parents received study information, completed eligibility screening with the trial coordinator, and consented to participate via the study website. Prior to randomisation, participants completed T1 assessment, consisting of: (i) parent-report questionnaires, in online $(n=95)$ or hardcopy $(n=12)$ format depending on parent preference; (ii) two weeks of symptom monitoring; and (iii) participation in an observation of a typical home treatment session.

Allocation was by block randomisation, using computer-generated randomly-selected block sizes $(4,6$, or 8 participants per block) and random group allocation within each block. An external researcher generated random allocation sequences, and prepared sequentiallynumbered opaque envelopes to conceal group allocation. Envelopes were assigned by a research assistant in the order families completed T1 assessment. Neither researchers nor participants were blinded to intervention group.

Families assigned to the Intervention group attended the intervention and repeated assessments at 4 weeks (T2) and 6 months (T3) post-intervention. Families assigned to CAU repeated assessments at 6 weeks (T2) and 6 months (T3) post-enrolment. On enrolment into the study all families, irrespective of group allocation, were instructed to continue their child's usual medical management, for example, attending appointments with their child's doctor/s and other health care professionals, and continuing to follow the child's medical management plan as normal. CAU families attended the program after completing T3 assessment.

\section{Intervention}

The intervention consists of two interactive 2-hour group discussion sessions, Positive Parenting for Healthy Living (Morawska \& Sanders, 2011), and draws on theoretical 
principles that form the basis of Triple P (Sanders, 2012). Proximal targets of the intervention are parenting skill and confidence relating to both general child behaviour, and specific to illness management; and parenting practices and family stress, which constitute direct and indirect pathways of parenting impact on child health and wellbeing (Wood et al., 2007). Teaching methods included didactic instruction, video modelling, active skills training, and homework tasks.

The intervention targets parents of 2-10 year-old children and strategies and examples are tailored to specific developmental and other needs during sessions. This may involve asking parents to consider how a strategy applies to their child, for example by reflecting how involving a child in their illness management differs for a 3-year-old versus and 10-year-old. The underlying principles for each strategy are the central focus, with examples used to illustrate flexible application.

The first session focuses on strategies to empower parents to prevent and manage problem behaviours and ensure that illness prevention and management plans are implemented appropriately. Topics include continuing regular activities; having realistic expectations; reducing stress; helping siblings cope; condition-specific management steps; involving the child; communicating with caregivers; keeping track of symptoms; and being prepared for emergencies. The second session introduces the principles of positive parenting in the context of child chronic illness management, to promote positive parenting practices, assist parents to develop effective disciplinary methods, and help create environments conducive to caring parent-child relationships. Key content includes causes of behaviour problems in children with chronic illnesses; parenting traps; use of routines to improve treatment management; preventing and managing anxiety; and behavioural strategies, including descriptive praise, positive attention, giving clear instructions, consequences, and behaviour charts. The strategies are presented with examples focusing on how they can be used in the context of 
illness management. Examples of how strategies would be implemented in the childhood chronic illness context were tailored depending on the specific concerns of parents in the group (e.g. medication/treatment refusal, child anxiety, sibling/peer conflict).

Program content is not condition-specific; rather, it addresses issues common to most childhood chronic health conditions. Condition-specific information was limited to takehome tip sheets providing accurate, up-to-date information on disease aetiology and management (1 for asthma, 1 for eczema), and brief videos demonstrating key management steps (1.5 minutes for asthma, and 3.5 minutes for eczema) that were played during the first session. Children frequently had older sibling/s with asthma, eczema, or both conditions; thus, the vast majority of parents wanted information about both conditions, and all sessions included group discussions about both conditions regardless of group composition.

Eighteen discussion groups were held at a university psychology clinic in metropolitan Brisbane, Australia, between August 2011 and December 2013. Groups comprised an average six parents $(M=6.56, S D=3.54)$ from four families $(M=4.44, S D=2.60)$. Sessions were facilitated by 10 accredited Triple $\mathrm{P}$ practitioners (psychologists or nurses).

\section{Assessment}

The Family Background Questionnaire (Sanders \& Morawska, 2010) was used to assess demographic variables.

Primary outcomes. Parent-report questionnaires. The modified Parents' Self-Efficacy with Eczema Care Index (PASECI; $\alpha=.96$ Charman, Venn, \& Williams, 2004) and the Asthma Parent Tasks Checklist (APTC) Confidence scale ( $\alpha=.93$; Morawska, Stelzer, \& Burgess, 2008) assessed parents' self-efficacy for performing tasks necessary to manage their child's eczema or asthma.

The Eczema Behaviour Checklist (EBC; Mitchell, Morawska, Sillar, \& Fraser, 2015) and the Asthma Behaviour Checklist (ABC; Morawska et al., 2008) assessed the extent to which 
parents experienced child behaviour problems related to eczema (EBC Extent; $\alpha=.92$ ) or asthma (ABC Extent; $\alpha=.93$ ), and their level of confidence with managing these behaviours (EBC Confidence, $\alpha=.95 ;$ ABC Confidence, $\alpha=.98$ ).

The PedsQL4.0: Pediatric Quality of Life Generic Core Scale (Varni, Seid, \& Kurtin, 2001) assessed child health-related quality of life (HRQL; $\alpha=.82$ ). The PedsQL Family Impact Module (Varni, Sherman, Burwinkle, Dickinson, \& Dixon, 2004) assessed parent $\operatorname{HRQL}(\alpha=.93)$ and family functioning $(\alpha=.92)$.

Secondary outcomes. Symptom monitoring. Parents recorded symptoms daily for 2 weeks at each time-point: whether (yes/no) skin was itchy, bleeding, cracked, flaking, rough, weeping or oozing, and sleep disturbance, and; number of asthma episodes, whether any were moderate-severe (i.e. >2 hours; interfered with play/school/sleep; led to shortening of normal activity, seeing a doctor, or going to hospital). Weekly scores were averaged to calculate mean eczema severity (Patient-Oriented Eczema Measure; POEM; Mitchell \& Fraser, 2011), mean asthma episodes/week, and mean number of days/week with moderate-severe episodes.

Observation. A routine at-home medical management session was observed at each timepoint, lasting a mean 4.93 minutes at $\mathrm{T} 1(S D=4.49$, range $0.5-28.5)$. For eczema, parents applied their child's usual topical treatments and/or wet-wraps. For asthma, parents administered two doses of a placebo metered dose inhaler (MDI).

Medical management sessions were videotaped, and competence with providing treatment was assessed by trained research assistants blind to condition. For eczema management, parents scored a maximum 11 points for applying adequate moisturiser; for asthma management, parents scored a maximum 5 points for correctly administering the MDI. A random $25 \%$ of sessions were assessed by a second research assistant. Intra-class correlations (ICC) indicated excellent inter-rater agreement for eczema $(\mathrm{ICC}=.97)$ and asthma $(\mathrm{ICC}=.76)$ treatment competence scores. 


\section{Protocol Adherence}

The intervention was delivered according to a standardised manual and treatment delivery protocol. Protocol adherence checklists completed by group facilitators indicated $100 \%$ of content was covered. Groups were digitally recorded and $25 \%(n=5)$ were independently coded, with $97.7 \%$ agreement between facilitators and an independent rater. No parents reported receiving additional parenting support during the study period.

\section{Statistical Analyses}

To detect a medium effect size $(d=.50), 128$ families were needed to provide $80 \%$ power with a type 1 error of $5 \%$ (two-tailed) for the primary hypotheses to be tested. Longitudinal intention-to-treat analyses were performed using mixed-model repeated-measures (MMRM) linear regression models in SPSS. In all, $7.2 \%$ of data were missing completely at random, and the full information maximum likelihood approach to handling missing data was applied. First, models containing fixed and random effects of time (T1/T2/T3) were assessed for a main effect of time (Model 1). Next, fixed effects of group and group-by-time interactions were added, and significant interaction terms indicated significant intervention effects (Model 2). To interpret direction of intervention effects, follow-up contrasts using models with fixed and random effects of time as predictors were run separately for Intervention and CAU groups (Models 3 and 4), and t-tests compared rate of change (regression parameter estimate for time) between groups. Where data variability was insufficient to support inclusion of random effect of time, the random effect was excluded from all four models. Analysis was conducted for all participants by originally assigned group. One extreme outlier was detected in each group for the number of asthma episodes/week at T3, and excluded from analyses using this variable.

On the assumption that intervention-driven improvements in symptom severity would most likely arise from improved adherence to the child's treatment regimen, we also conducted 
exploratory post-hoc sub-group analyses to compare change in symptom severity for those children whose treating doctors had prescribed preventer medications or topical steroids for asthma or eczema treatment, respectively, and those whose doctors had not. We anticipated greater improvement where children had been prescribed corticosteroid medications, which are typically administered once or more daily, as these parents would have more frequent opportunities to face resistance to treatment from their child, and improved adherence should, theoretically, result in the greatest improvements in symptom severity post-intervention.

\section{Results}

\section{Sample}

Of 164 parents who expressed interest, 148 met eligibility criteria, and 107 consented to participate, completed T1 assessment, and were randomly allocated. Progress of participants through the study is detailed in Figure 1. Baseline characteristics of participants are provided in Table 1 and there were no significant differences between groups at baseline.

Age at diagnosis was birth- 8 years for eczema and 6 months- 8 years for asthma. For eczema, $90 \%$ were diagnosed by age 2 , and $68 \%$ by age 1 . For asthma, $60 \%$ were diagnosed by age 2 . Doctors reported prescribing topical corticosteroids for $70 \%(59)$ of children with eczema and inhaled corticosteroids for $68 \%(32)$ of children with asthma.

For eczema, mean POEM scores at T1 classified children's eczema as clear/almost clear $(2 \%, 2)$, mild $(11 \%, 9)$, moderate $(54 \%, 45)$, severe $(27 \%, 22)$, or very severe $(6 \%, 5)$ (POEM $M=13.76, S D=5.90$, range 0-28). During T1 asthma symptom monitoring, $70 \%(30)$ experienced $\geq 1$ asthma episodes $(M=2.35 /$ week, $S D=2.88$, range $0-23)$, and $18 \%(8)$ had $\geq 1$ day/week where an episode lasted $>2$ hours $(M=0.27, S D=0.72)$. On $\geq 1$ day/week, asthma interfered with activity/play/school/sleep for 66\%(29) $(M=1.44, S D=1.72)$, shortened normal activity for $48 \%(21)(M=1.01, S D=1.52)$, and led to seeing a doctor for $14 \%(6)$.

\section{Attrition}


Of parents allocated to Intervention, 40(77\%) attended both sessions, 5(10\%) attended one session, and 7(13\%) did not receive the intervention. Of the final sample ( $n=107), 95(89 \%)$ completed T2 assessment: of the Intervention group parents, 5 did not attend the sessions and withdrew prior to T2, 1 was unable to be contacted after initial enrolment, and 2 attended groups but withdrew prior to T2. A further 2 parents withdrew prior to T3. In the CAU group, 4 parents withdrew before T2, and another 6 families withdrew prior to T3. The proportion of participants lost to follow-up did not differ significantly between Intervention (10/52) and CAU (10/55) groups, $\chi^{2}(1, n=107)=0, P=1.00$. No adverse effects, concerns, or unintended consequences were identified.

\section{Intervention Effects}

Means, standard deviations, and effect sizes (Cohen's $d$ ) for eczema, asthma, and HRQL outcomes are presented in Tables 2, 3, and 4, respectively. Results of MMRM analyses are presented in Table 5.

Parents' self-efficacy. Time predicted improvement in confidence with performing eczema management tasks (PASECI) (see Table 5). A significant time-by-group interaction indicated a significant intervention effect, such that the Intervention group showed greater improvement over the 6 months post-intervention compared to the CAU group, who showed no significant change.

Conversely, time did not predict change in confidence with performing asthma management tasks (APTC Confidence) (see Table 5). The time-by-group interaction was not significant, and there was no difference between groups on rate of change, with neither group showing significant change.

Child behaviour. Time predicted improvement in extent of eczema-related behaviour difficulties (EBC Extent), as well as parents' self-efficacy for dealing with them (EBC Confidence) (see Table 5). Time-by-group interactions were significant, indicating significant 
intervention effects for both Extent and Confidence. Improvement in EBC Extent scores was greater for the Intervention group, although CAU also demonstrated a smaller but statistically significant improvement. Improvement in EBC Confidence scores was also greater in the Intervention group, and only the Intervention group showed significant improvement.

Conversely, time did not predict change in extent of asthma-related behaviour difficulties (ABC Extent) or parents' self-efficacy for dealing with them (ABC Confidence) (see Table 5). Time-by-group interactions were not significant, and follow-up contrasts found no difference between groups on rate of change. Notably, mean item scores for behaviour problems at baseline were somewhat higher for eczema-related behaviours (EBC Extent; $M=3.57, S D=1.11$ ) compared to asthma-related behaviours (ABC Extent; $M=2.13, S D=0.97$ ). Parents' mean confidence scores at baseline for managing eczema (EBC Confidence; $M=7.10, S D=1.59$ ) were somewhat lower compared with managing asthma (ABC Confidence; $M=8.35, S D=1.77)$.

HRQL. Time predicted improvement in children's HRQL (PedsQL Total) (see Table 5). The time-by-group interaction was not significant, indicating no significant intervention effect. Both groups showed significant improvement, with no significant difference in rate of change between groups.

Time predicted improvement for both PedsQL Parent HRQL and Family Functioning scores (see Table 5). Time-by-group interactions were significant, indicating significant intervention effects for both variables. The Intervention group showed greater improvement for both measures compared to CAU, which did not show significant change over time.

Symptom severity. Time did predict decrease in eczema severity (POEM scores), and the time-by-group interaction was not significant $(p=.052)$ (see Table 5). Decrease in POEM scores was greater for the Intervention group compared to CAU, where there was no significant change. At T2 and T3, 39\% (12/31) and 56\% (18/32) of the Intervention group 
demonstrated clinically significant improvement (decrease of $\geq 3.4$ points) (Schram et al., 2012) compared to $22 \%(9 / 41)$ and $34 \%$ (13/38) of the CAU group. Exploratory sub-group analyses (see Table 6) showed that for children prescribed topical corticosteroids (Intervention $n=23, \mathrm{CAU} n=36$ ) the time-by-group interaction was significant, and the decrease in eczema severity was significantly greater for the Intervention group, with large effect size $(d=.95,95 \%$ CI $0.36-1.54)$. Conversely, for children not prescribed topical corticosteroids (Intervention $n=15$, CAU $n=10$ ), the time-by-group interaction was not significant, and there was no significant change for either group (see Table 6). Plots of regression slopes for change in eczema severity (POEM scores) over time for Intervention and CAU sub-groups are presented in Figure 2.

Time did not predict change in mean asthma episodes/week (see Table 5). The time-bygroup interaction was significant, indicating a significant intervention effect. The decrease in asthma episodes was greater for the Intervention group compared to CAU, who showed no significant change. Sub-group analyses (see Table 6) showed that for children prescribed a preventer (Intervention $n=14$, CAU $n=16$ ) there was a significant time-by-group interaction, such that the Intervention group showed a significant decrease in asthma episodes compared to CAU where there was no significant change, with large effect size (T1-T3 $d=1.19,95 \% \mathrm{CI}$ 0.36-2.02). Conversely, for children not prescribed a preventer (Intervention $n=9$, CAU $n=6$ ) the time-by-group interaction was not significant, and there was no significant change for either group (see Table 6). Plots of regression slopes for change in asthma episodes per week over time for Intervention and CAU sub-groups are presented in Figure 3.

Time did predict decrease in mean days/week where asthma episodes were moderatesevere (see Table 5). The time-by-group interaction was not significant $(p=.07)$. There was a significant decrease in the Intervention group, but no change for CAU, and the difference in rate of change between the groups approached significance $(p=.08)$ (see Table 5). 
Exploratory sub-group analyses (see Table 6) showed that for children with asthma prescribed a preventer, the time-by-group interaction was not significant $(p=.051)$, and the Intervention group showed a significant decrease in days with moderate-severe asthma episodes compared to CAU, where there was no significant change. The difference between groups was not significant, with a medium effect size (T1-T3 $d=.67,95 \% \mathrm{CI}-.11-1.46$ ). Conversely, for children not prescribed a preventer the time-by-group interaction was not significant, and there was no significant change for either group (see Table 6).

Observed parent competence with management. Time did not predict change in scores for eczema or asthma management competence, and time-by-group interactions were not significant, indicating no intervention effect (see Table 5). There were no differences by group on rate of change of scores, which did not change significantly over time for either group.

\section{Discussion}

Childhood illness management rarely targets parenting practices or confidence; thus, the results of this trial are particularly important. While intervention effects depended to an extent on whether children had asthma or eczema, parents reported greater confidence with illness management, fewer child behaviour difficulties, as well as better parent and family quality of life (Table 5). There were also improvements in clinical outcomes for children with both asthma and eczema, particularly for those children prescribed corticosteroid-based treatments (Table 6).

There were some inconsistencies in the findings worthy of note. Intervention effects for parent confidence and child behaviour held only for eczema outcomes, and not asthma outcomes. Although the relatively smaller size of the asthma sub-sample may have limited our ability to detect significant effects, particularly in the case of parents' asthma management self-efficacy, the effect sizes for the asthma-specific child behaviour extent and 
confidence were nevertheless much smaller compared to those for eczema (Tables 3 and 2, respectively). Equivocal results have previously been reported for parenting intervention in the context of asthma (Clarke et al., 2014). In this study, at baseline parents had more confidence with managing asthma behaviours than eczema behaviours, leaving less room for improvement. Furthermore, eczema management tends to be more time consuming and complicated, thus differential intervention effects may be due to the heterogeneity of the children's presentation and resulting parenting challenges. Finally, there is growing evidence that preventive (steroid) interventions are not effective for the majority of children with viral induced wheeze aged $<6$ years, thus diluting the impact of any intervention designed to enhance treatment competence on treatment outcomes in younger children (Bush, Grigg, \& Saglani, 2014). There were significant improvements in child HRQL for Intervention and CAU groups, resulting in no significant difference between Intervention and CAU groups (Table 5). The effect size for this result was very small at time 3 ( $d=.15$, see Table 4$)$, perhaps reflecting small improvements over time as children mature and become more adept at managing the impact of their illness. There was no change in observed treatment competence (Table 5), although this was not a direct target of the intervention, and points to the need for further parent education and training in effective treatment.

Notably, symptom severity improved, and effects were more pronounced for children with prescribed corticosteroid medication (Figures 2 and 3). These analyses were conducted on the assumption that intervention-driven improvements in symptom severity would most likely arise from improved adherence to the child's treatment regimen. We anticipated greater improvement where children had been prescribed corticosteroid medications, as these parents would have more frequent opportunities to face resistance to treatment from their child. With more opportunities to practice and implement parenting strategies, the impact on adherence should be greater, resulting in the more improvements in symptom severity post-intervention. 
Effect sizes were in the moderate-high range, and highest at 6-month follow-up (Tables 2 and 3). Analyses were considerably underpowered, as only a proportion of children had each condition. Importantly, for children with asthma in the intervention condition at T3 the number of episodes/week had reduced below one, while it had remained above the guideline level of two (Global Initative for Asthma, 2015) for children in CAU (Table 3). These results are very promising and point to the importance of conducting further research specifically examining treatment adherence and health outcomes in children.

The comparatively high rate of participation, good session attendance, and modest attrition demonstrates that even when faced with the additional pressure of managing a child with a chronic condition, parents can be engaged and retained in a brief, group parenting program specific to childhood illness and behaviour management. This is an important finding because translation and dissemination of parenting programs has been constrained by poor uptake and fragmented parental involvement (Hindman, Brooks, \& van der Zwan, 2012). The program was delivered over two, short sessions, held a week apart on weeknights or Saturdays to reduce barriers to participation. It may be that the brief time commitment to the intervention may have eased many of the barriers parents often experience to participating in any parenting program (e.g., finding childcare, timing of sessions, time commitment).

Some caution should be applied to interpretation of findings as a number of limitations are acknowledged. Firstly, measures were well validated, but the study relied largely on parentreport. Future studies should focus on objective assessment of both treatment adherence and illness severity. Future trials should also test for any impact of the intervention on patterns of health care usage (e.g. routine medical reviews, emergency presentations) as this was beyond the scope of the current study. The design of this trial did not allow for specific testing of mechanisms that might contribute to change. The precise relationship between improved parenting and child health outcomes is not well understood, and the effect of augmenting the 
standard behavioural parenting program with strategies to manage resistant behaviours remains to be tested. Finally, families were unselected, and generally of higher socioeconomic status; thus, generalisability of these findings remains to be tested.

\section{Conclusion}

Our study indicates that a brief parenting intervention tailored for parents of chronically ill children can lead to significant benefits in parental illness management self-efficacy, child behaviour and family quality of life, however, this may depend on the initial type and severity of the condition. Effects differed by child illness condition, suggesting the need to explore moderators of outcome and potential pathways of effect depending on the nature of the illness and the corresponding parenting tasks. While underpowered, our study also provided strong evidence for reductions in symptom severity. This is a highly important finding as it demonstrates that an intervention focused on improving parenting can lead to improvements in child health outcomes.

\section{Acknowledgements}

We gratefully acknowledge all the families who were involved in this trial. 


\section{References}

Asher, M. I., Montefort, S., Björkstén, B., Lai, C. K. W., Strachan, D. P., Weiland, S. K., . . . Group, I. P. T. S. (2006). Worldwide time trends in the prevalence of symptoms of asthma, allergic rhinoconjunctivitis, and eczema in childhood: ISAAC Phases One and Three repeat multicountry cross-sectional surveys. Lancet, 368(9537), 733 - 743.

Bush, A., Grigg, J., \& Saglani, S. (2014). Managing wheeze in preschool children. BMJ, 348.

Charman, C. R., Venn, A. J., \& Williams, H. C. (2004). The Patient-Oriented Eczema Measure: Development and initial validation of a new tool for measuring atopic eczema severity from the patients' perspective. Archives of Dermatology, 140, 15131519.

Clarke, S. A., Calam, R., Morawska, A., \& Sanders, M. (2014). Developing web-based Triple $\mathrm{P}$ 'Positive Parenting Programme' for families of children with asthma. Child: Care, Health and Development, 40(4), 492-497.

Dean, A. J., Walters, J., \& Hall, A. (2010). A systematic review of interventions to enhance medication adherence in children and adolescents with chronic illness. Archives of Disease in Childhood, 95(9), 717-723.

Doherty, F. M., Calam, R., \& Sanders, M. R. (2013). Positive Parenting Program (Triple P) for Families of Adolescents With Type 1 Diabetes: A Randomized Controlled Trial of Self-Directed Teen Triple P. Journal of Pediatric Psychology, 38(8), 846-858.

Eccleston, C., Palermo Tonya, M., Fisher, E., \& Law, E. (2012). Psychological interventions for parents of children and adolescents with chronic illness. Cochrane Database of Systematic Reviews, (8). Retrieved from doi:10.1002/14651858.CD009660.pub2

Ersser, S., J., Cowdell, F., Latter, S., Gardiner, E., Flohr, C., Thompson, A., Robert, . . Drury, A. (2014). Psychological and educational interventions for atopic eczema in 
children. Cochrane Database of Systematic Reviews, (1). Retrieved from doi:10.1002/14651858.CD004054.pub3

Global Initative for Asthma. (2015). Global Strategy for Asthma Management and Prevention. www.ginasthma.org.

Hindman, E., Brooks, A., \& van der Zwan, R. (2012). Parenting program uptake: Impacts of implementation factors on intention to enrol. Advances in Mental Health, 10(2), 127137.

Holmbeck, G. N., Johnson, S. Z., Wills, K. E., McKernon, W., Rose, B., Erklin, S., \& Kemper, T. (2002). Observed and perceived parental overprotection in relation to psychosocial adjustment in preadolescents with a physical disability: The mediational role of behavioral autonomy. Journal of Consulting \& Clinical Psychology, 70, 96110.

Kirk, S., Beatty, S., Callery, P., Gellatly, J., Milnes, L., \& Pryjmachuk, S. (2012). The effectiveness of self-care support interventions for children and young people with long-term conditions: a systematic review. Child: care, health and development, $39(3), 305-324$.

Law, E. F., Fisher, E., Fales, J., Noel, M., \& Eccleston, C. (2014). Systematic Review and Meta-Analysis of Parent and Family-Based Interventions for Children and Adolescents With Chronic Medical Conditions. Journal of Pediatric Psychology, 39(8), 866-886.

Lohan, A., Morawska, A., \& Mitchell, A. (2015). A Systematic Review of Parenting Interventions for Parents of Children with Type 1 Diabetes. Child: Care, Health \& Development 41(6), 803-817. 
Mitchell, A., Morawska, A., Sillar, K., \& Fraser, J. (2015). Child Behaviour Problems and Childhood Illness: Development of the Eczema Behaviour Checklist Submitted for publication.

Mitchell, A. E., \& Fraser, J. A. (2011). Parents' self-efficacy, outcome expectations, and selfreported task performance when managing atopic dermatitis in children: Instrument reliability and validity International Journal of Nursing Studies, 28(2), 215-226

Morawska, A., Calam, R., \& Fraser, J. (2015). Parenting interventions for childhood chronic illness: A review and recommendations for intervention design and delivery. Journal of Child Health Care 19(1), 5-17.

Morawska, A., Mitchell, A., Burgess, S., \& Fraser, J. (2015). Randomised controlled trial of Triple $\mathrm{P}$ for parents of children with asthma or eczema: Effects on parenting and child behaviour. Submitted for publication.

Morawska, A., \& Sanders, M. R. (2011). Positive Parenting for Healthy Living Parent Discussion Group. Brisbane: Parenting and Family Support Centre, The University of Queensland.

Morawska, A., Stelzer, J., \& Burgess, S. W. (2008). Parenting asthmatic children: Identification of parenting challenges. Journal of Asthma, 45, 465-472.

Morton, R. W., Everard, M. L., \& Elphick, H. E. (2014). Adherence in childhood asthma: the elephant in the room. Arch Dis Child, 99(10), 949-953.

Mrazek, D., Klinnert, M., Mrazek, P., Ikle, D., Brower, A., \& McCormick, D. (1999). Prediction of early onset asthma in genetically at risk children. Pediatric Pulmonology, 27, 85-94.

O'Connell, M. E., Boat, T., \& Warner, K. E. (Eds.). (2009). Preventing Mental, Emotional, and Behavioral Disorders Among Young People: Progress and Possibilities. Washington, DC: National Academic Press. 
Pinquart, M. (2012). Self-esteem of children and adolescents with chronic illness: a metaanalysis. child: Care Health and Development.

Pinquart, M. (2013). Do the Parent-Child Relationship and Parenting Behaviors Differ Between Families With a Child With and Without Chronic Illness? A Meta-Analysis. Journal of Pediatric Psychology, 38(7), 708-721.

Pinquart, M., \& Shen, Y. (2011). Behavior Problems in Children and Adolescents With Chronic Physical Illness: A Meta-Analysis. Journal of Pediatric Psychology, 36(9), $1003-1016$.

Pinquart, M., \& Teubert, D. (2012). Academic, Physical, and Social Functioning of Children and Adolescents With Chronic Physical Illness: A Meta-analysis. Journal of Pediatric Psychology 37(4), 376-389.

Rohan, J. M., Rausch, J. R., Pendley, J. S., Delamater, A. M., Dolan, L., Reeves, G., \& Drotar, D. (2014). Identification and prediction of group-based glycemic control trajectories during the transition to adolescence. Health Psychology, 33(10), 11431152.

Sanders, M. R. (2012). Development, Evaluation, and Multinational Dissemination of the Triple P-Positive Parenting Program. Annual Review of Clinical Psychology, 8, 345379.

Sanders, M. R., \& Morawska, A. (2010). Family Background Questionnaire. Brisbane: Parenting and Family Support Centre.

Sassmann, H., de Hair, M., Danne, T., \& Lange, K. (2012). Reducing stress and supporting positive relations in families of young children with type 1 diabetes: A randomized controlled study for evaluating the effects of the DELFIN parenting program. BMC Pediatrics, 12(1), 152. 
Schram, M. E., Spuls, P. I., Leeflang, M. M. G., Lindeboom, R., Bos, J. D., \& Schmitt, J. (2012). EASI, (objective) SCORAD and POEM for atopic eczema: responsiveness and minimal clinically important difference. Allergy, 67, 99-106.

Van Cleave, J., Gortmaker, S. L., \& Perrin, J. M. (2010). Dynamics of obesity and chronic health conditions among children and youth. JAMA, 303(7), 623-630.

Varni, J. W., Seid, M., \& Kurtin, P. S. (2001). The PedsQL ${ }^{\text {TM }}$ 4.0: Reliability and validity of the Pediatric Quality of Life Inventory ${ }^{\mathrm{TM}}$ Version 4.0 Generic Core Scales in healthy and patient populations. Medical Care, 39, 800-812.

Varni, J. W., Sherman, S. A., Burwinkle, T. M., Dickinson, P. E., \& Dixon, P. (2004). The PedsQL Family Impact Module: Preliminary reliability and validity. Health and Quality of Life Outcomes, 2(55), 1-6.

Westrupp, E. M., Northam, E., Lee, K. J., Scratch, S. E., \& Cameron, F. (2015). Reducing and preventing internalizing and externalizing behavior problems in children with type 1 diabetes: a randomized controlled trial of the Triple P-Positive Parenting Program. Pediatric Diabetes, 16(7), 554-563.

Wood, B. L., Lim, J., Miller, B. F., Cheah, P., Zwetsch, T., Ramesh, S., \& Simmens, S. (2008). Testing the Biobehavioral Family Model in Pediatric Asthma: Pathways of Effect. Family Process, 47, 21-40.

Wood, B. L., Lim, J. H., Miller, B. D., Cheah, P. A., Simmens, S., \& Stern, T. (2007). Family emotional climate, depression, emotional triggering of asthma, and disease severity in pediatric asthma: Examination of pathways of effect. Journal of Pediatric Psychology, 32, 542-551. 


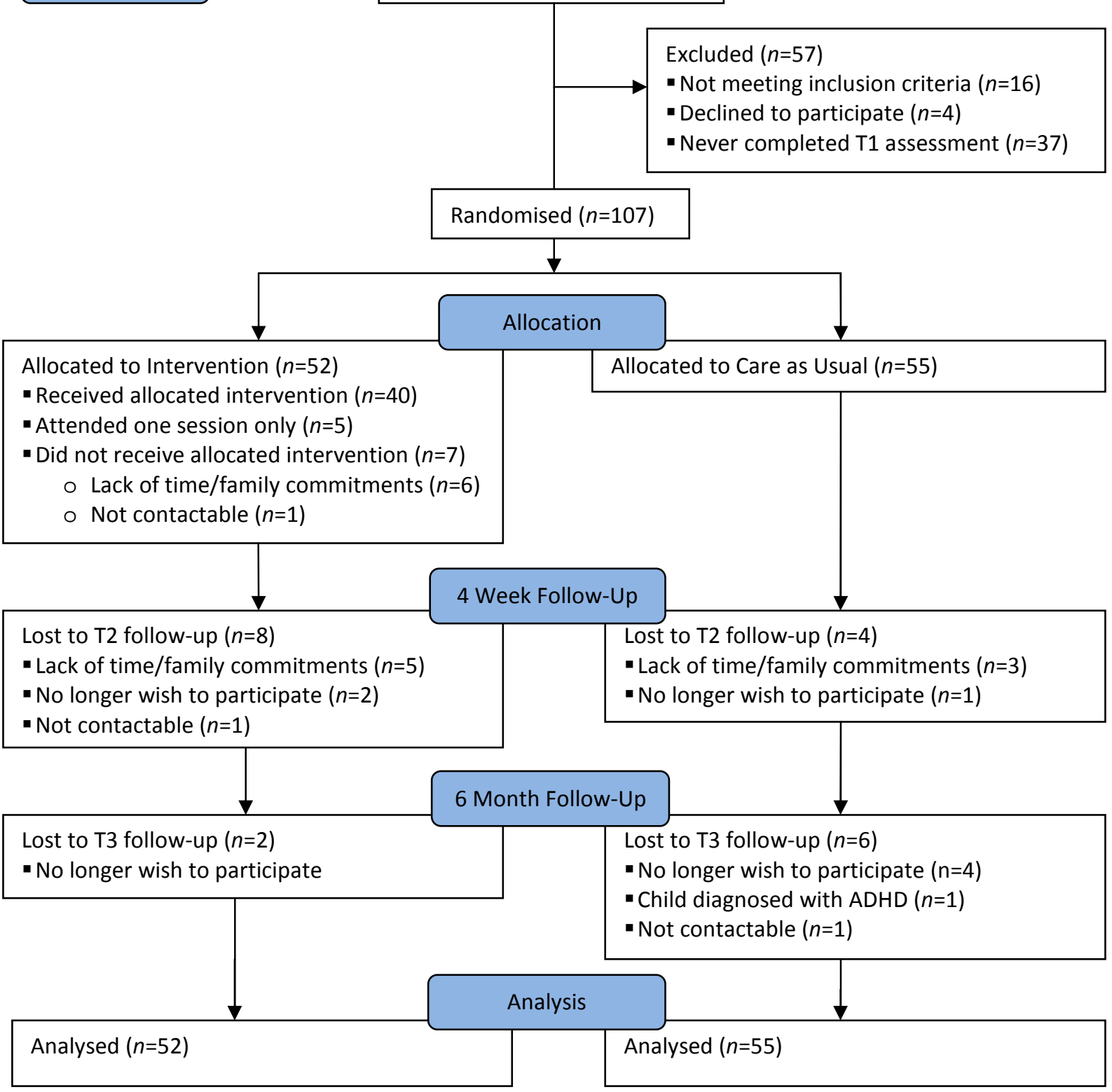

Figure 1. CONSORT diagram of flow of participants 
Table 1. Demographic and clinical characteristics of participants by group

\begin{tabular}{|c|c|c|c|c|}
\hline Variables & & Intervention $(n=52)$ & Care as Usual $(n=55)$ & \\
\hline Parent's age (years) & & $36.69(5.20)$ & $37.84(4.94)$ & 1.05 \\
\hline Child's age (years) & & $5.02(2.14)$ & $5.05(2.26)$ & 0.17 \\
\hline $\begin{array}{l}\text { Child's age at } \\
\text { diagnosis (years) }\end{array}$ & $\begin{array}{l}\text { Eczema }^{\mathrm{a}} \\
\text { Asthma }^{\mathrm{b}}\end{array}$ & $\begin{array}{l}0.79(1.05) \\
2.79(1.69)\end{array}$ & $\begin{array}{l}1.04(1.63) \\
2.55(1.66)\end{array}$ & $\begin{array}{r}0.84 \\
-0.53\end{array}$ \\
\hline $\begin{array}{l}\text { Symptom severity at } \\
\text { baseline }\end{array}$ & $\begin{array}{l}\text { Asthma episodes / week } \\
\text { Eczema severity (POEM) }^{\mathrm{c}}\end{array}$ & $\begin{array}{r}2.38(3.33) \\
13.46(6.37)\end{array}$ & $\begin{array}{r}2.32(2.44) \\
14.01(5.54)\end{array}$ & $\begin{array}{r}-0.07 \\
0.42\end{array}$ \\
\hline & $\begin{array}{l}\text { Clear / almost clear } \\
\text { Mild } \\
\text { Moderate } \\
\text { Severe } \\
\text { Very severe }\end{array}$ & $\begin{array}{c}\%(n) \\
5(2) \\
13(5) \\
45(17) \\
34(13) \\
3(1)\end{array}$ & $\begin{array}{c}\%(n) \\
- \\
9(4) \\
62(28) \\
20(9) \\
9(4)\end{array}$ & $\frac{\chi^{2}}{-\mathrm{d}}$ \\
\hline Diagnoses & $\begin{array}{l}\text { Asthma } \\
\text { Eczema } \\
\text { Both asthma and eczema }\end{array}$ & $\begin{array}{l}48(25) \\
75(39) \\
26(14)\end{array}$ & $\begin{array}{l}42(23) \\
84(46) \\
23(12)\end{array}$ & $\begin{array}{l}0.21 \\
0.75 \\
0.00\end{array}$ \\
\hline $\begin{array}{l}\text { Previous hospital } \\
\text { separation (yes) }\end{array}$ & $\begin{array}{l}\text { Eczema }^{\mathrm{a}} \\
\text { Asthma }^{\mathrm{b}}\end{array}$ & $\begin{array}{l}19(7) \\
33(7)\end{array}$ & $\begin{array}{l}11(5) \\
48(10)\end{array}$ & $\begin{array}{l}0.48 \\
0.40\end{array}$ \\
\hline Child's sex & $\begin{array}{l}\text { Male } \\
\text { Female }\end{array}$ & $\begin{array}{l}52(27) \\
48(25)\end{array}$ & $\begin{array}{l}53(29) \\
47(26)\end{array}$ & 0.00 \\
\hline Ethnicity & $\begin{array}{l}\text { Caucasian } \\
\text { Asian } \\
\text { Pacific Islander }^{\mathrm{e}} \\
\text { Not specified }^{\mathrm{e}}\end{array}$ & $\begin{array}{l}87(45) \\
8(4) \\
2(1) \\
4(2)\end{array}$ & $\begin{array}{l}84(46) \\
13(7) \\
- \\
4(2)\end{array}$ & 0.25 \\
\hline Household & $\begin{array}{l}\text { Original family } \\
\text { Sole parent / step family }\end{array}$ & $\begin{array}{l}89(46) \\
11(6)\end{array}$ & $\begin{array}{l}76(42) \\
24(13)\end{array}$ & 1.91 \\
\hline $\begin{array}{l}\text { Parent's relationship } \\
\text { to child }\end{array}$ & $\begin{array}{l}\text { Mother } \\
\text { Father }\end{array}$ & $\begin{array}{c}92(48) \\
8(4)\end{array}$ & $\begin{array}{l}96(53) \\
4(2)\end{array}$ & 0.24 \\
\hline Parent's education & $\begin{array}{l}\text { High school or less } \\
\text { Trade/college } \\
\text { University degree } \\
\text { Postgraduate degree }\end{array}$ & $\begin{array}{l}12(6) \\
23(12) \\
52(27) \\
14(7)\end{array}$ & $\begin{array}{l}24(13) \\
9(5) \\
42(23) \\
26(14)\end{array}$ & 8.34 \\
\hline Relationship status & $\begin{array}{l}\text { Married/de facto } \\
\text { Separated/divorced/single }\end{array}$ & $\begin{array}{r}90(47) \\
10(5)\end{array}$ & $\begin{array}{l}78(43) \\
22(12)\end{array}$ & 2.14 \\
\hline Parent's employment & $\begin{array}{l}\text { Full-time/part-time } \\
\text { Not working/job seeking }\end{array}$ & $\begin{array}{l}67(35) \\
33(17)\end{array}$ & $\begin{array}{l}62(34) \\
38(21)\end{array}$ & 0.15 \\
\hline $\begin{array}{l}\text { Able to meet } \\
\text { essential expenses }{ }^{\mathrm{f}}\end{array}$ & $\begin{array}{l}\text { Yes } \\
\text { No } \\
\text { Don't know }\end{array}$ & $\begin{array}{l}81(42) \\
17(9) \\
2(1)\end{array}$ & $\begin{array}{l}86(47) \\
13(7) \\
2(1)\end{array}$ & 0.16 \\
\hline
\end{tabular}




\begin{tabular}{|c|c|c|c|}
\hline \multirow{3}{*}{$\begin{array}{l}\text { After expenses can } \\
\text { afford }\end{array}$} & Not much & $15(8)$ & $16(9)$ \\
\hline & Some things & $54(28)$ & $47(26)$ \\
\hline & Most things & $31(16)$ & $36(20)$ \\
\hline
\end{tabular}

Abbreviation: POEM, Patient Oriented Eczema Measure (0-2 = clear $/$ almost clear; 3-7 = mild; 8-16 = moderate; $17-24$ = severe; $25-28$ = very severe).

${ }^{\mathrm{a}}$ MIssing data for Intervention $n=3$, Care as Usual $n=2$. ${ }^{\mathrm{b}}$ MIssing data for Intervention $n=4$, Care as Usual $n$ $=2 .{ }^{\mathrm{C}}$ Missing data for Intervention $=1$, Care as Usual $=1 .{ }^{\mathrm{d}}$ Chi-square test for independence not performed as 6 expected cell frequencies $<5$. ${ }^{\text {e}}$ Cases excluded from chi-square test for independence as observed frequencies $<5$. ${ }^{f}$ Able to meet essential household expenses during the past 12 months. 
Table 2. Means and standard deviations for eczema outcomes by treatment condition, and effect sizes

\begin{tabular}{|c|c|c|c|c|c|c|c|c|}
\hline & \multicolumn{3}{|c|}{ Intervention $(n=39)$} & \multicolumn{3}{|c|}{ Care as Usual $(n=46)$} & \multicolumn{2}{|c|}{ Effect size $^{a}$} \\
\hline & T1 & $\mathrm{T} 2$ & T3 & T1 & $\mathrm{T} 2$ & T3 & T1-T2 & T1-T3 \\
\hline \multirow[t]{2}{*}{ Measure } & $\begin{array}{c}M \\
(S D)\end{array}$ & $\begin{array}{c}M \\
(S D)\end{array}$ & $\begin{array}{c}M \\
(S D)\end{array}$ & $\begin{array}{c}M \\
(S D)\end{array}$ & $\begin{array}{c}M \\
(S D)\end{array}$ & $\begin{array}{c}M \\
(S D)\end{array}$ & $\begin{array}{c}d \\
{[95 \% \mathrm{CI}]}\end{array}$ & $\begin{array}{c}d \\
{[95 \% \mathrm{CI}]}\end{array}$ \\
\hline & $n$ & $n$ & $n$ & $n$ & $n$ & $n$ & & \\
\hline \multirow{3}{*}{$\begin{array}{l}\text { Self-efficacy with eczema } \\
\text { management }^{b}\end{array}$} & 7.05 & 8.01 & 8.06 & 7.71 & 7.93 & 8.01 & 0.54 & 0.49 \\
\hline & $(1.57)$ & $(1.26)$ & $(1.70)$ & $(1.63)$ & $(1.33)$ & $(1.16)$ & {$[0.08-1.00]$} & {$[0.01-0.97]$} \\
\hline & 38 & 34 & 32 & 46 & 43 & 37 & & \\
\hline \multirow{3}{*}{$\begin{array}{l}\text { Self-efficacy with eczema } \\
\text { behaviour management }{ }^{c}\end{array}$} & 166.45 & 200.38 & 207.03 & 186.65 & 196.40 & 191.14 & 0.64 & 1.00 \\
\hline & $(38.06)$ & $(29.59)$ & $(31.93)$ & $(39.20)$ & $(31.80)$ & $(45.04)$ & {$[0.18-1.10]$} & {$[0.50-1.50]$} \\
\hline & 38 & 34 & 32 & 46 & 43 & 37 & & \\
\hline \multirow{3}{*}{$\begin{array}{l}\text { Extent of eczema } \\
\text { behaviour difficulties }^{\mathrm{d}}\end{array}$} & 94.58 & 78.62 & 63.78 & 84.87 & 77.19 & 74.68 & 0.19 & 0.65 \\
\hline & $(28.95)$ & $(28.61)$ & $(24.99)$ & $(26.37)$ & $(28.60)$ & $(26.18)$ & {$[-0.26-0.64]$} & [0.16-1.13] \\
\hline & 38 & 34 & 32 & 46 & 43 & 37 & & \\
\hline \multirow[t]{3}{*}{ Eczema symptom severity ${ }^{\mathrm{e}}$} & 13.46 & 10.97 & 9.31 & 14.01 & 13.52 & 12.11 & 0.42 & 0.55 \\
\hline & $(6.37)$ & $(6.12)$ & $(6.03)$ & $(5.54)$ & $(5.99)$ & $(5.43)$ & {$[-0.05-0.88]$} & {$[0.07-1.02]$} \\
\hline & 38 & 31 & 32 & 45 & 41 & 38 & & \\
\hline \multirow{3}{*}{$\begin{array}{l}\text { Competence with eczema } \\
\text { management (observed })^{\mathrm{f}}\end{array}$} & 6.69 & 8.41 & 7.63 & 7.09 & 6.93 & 6.59 & 0.17 & 0.34 \\
\hline & $(4.27)$ & $(3.43)$ & $(4.01)$ & (4.13) & (3.91) & $(4.10)$ & {$[-0.30-0.65]$} & {$[-0.17-0.85]$} \\
\hline & 39 & 29 & 27 & 46 & 41 & 32 & & \\
\hline \multicolumn{9}{|c|}{ 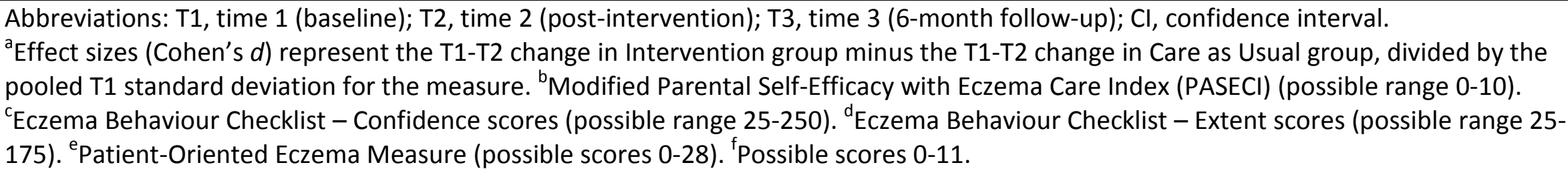 } \\
\hline
\end{tabular}


Table 3. Means and standard deviations for asthma outcomes by treatment condition, and effect sizes

\begin{tabular}{|c|c|c|c|c|c|c|c|c|}
\hline & \multicolumn{3}{|c|}{ Intervention $(n=25)$} & \multicolumn{3}{|c|}{ Care as Usual $(n=23)$} & \multicolumn{2}{|c|}{ Effect size $^{a}$} \\
\hline & T1 & $\mathrm{T} 2$ & T3 & T1 & $\mathrm{T} 2$ & $\mathrm{~T} 3$ & T1-T2 & T1-T3 \\
\hline \multirow[t]{2}{*}{ Measure } & $\begin{array}{c}M \\
(S D)\end{array}$ & $\begin{array}{c}M \\
(S D)\end{array}$ & $\begin{array}{c}M \\
(S D)\end{array}$ & $\begin{array}{c}M \\
(S D)\end{array}$ & $\begin{array}{c}M \\
(S D)\end{array}$ & $\begin{array}{c}M \\
(S D)\end{array}$ & $\begin{array}{c}d \\
{[95 \% \mathrm{CI}]}\end{array}$ & $\begin{array}{c}d \\
{[95 \% \mathrm{CI}]}\end{array}$ \\
\hline & $n$ & $n$ & $n$ & $n$ & $n$ & $n$ & & \\
\hline \multirow{3}{*}{$\begin{array}{l}\text { Self-efficacy with asthma } \\
\text { management }^{\mathrm{b}}\end{array}$} & 134.29 & 136.65 & 135.63 & 140.26 & 137.27 & 128.95 & 0.35 & 0.63 \\
\hline & (27.37) & (33.64) & (39.64) & (23.16) & (20.13) & (37.36) & {$[-0.26-0.95]$} & [0.00-1.27] \\
\hline & 24 & 20 & 19 & 23 & 22 & 21 & & \\
\hline \multirow{3}{*}{$\begin{array}{l}\text { Self-efficacy with asthma } \\
\text { behaviour management }^{\mathrm{c}}\end{array}$} & 184.83 & 187.75 & 186.21 & 182.74 & 189.32 & 173.62 & -0.02 & 0.24 \\
\hline & (36.76) & (41.34) & (47.34) & $(41.82)$ & (21.24) & (47.37) & {$[-0.62-0.58]$} & {$[-0.38-0.86]$} \\
\hline & 24 & 20 & 19 & 23 & 22 & 21 & & \\
\hline \multirow{3}{*}{$\begin{array}{l}\text { Extent of asthma } \\
\text { behaviour difficulties }^{\mathrm{d}}\end{array}$} & 46.29 & 47.30 & 43.84 & 47.30 & 48.50 & 43.33 & 0.10 & 0.05 \\
\hline & (23.05) & $(28.23)$ & (21.61) & (19.77) & (24.64) & (23.71) & {$[-0.51-0.70]$} & {$[-0.57-0.66]$} \\
\hline & 24 & 20 & 19 & 23 & 22 & 21 & & \\
\hline \multirow{3}{*}{$\begin{array}{l}\text { Number of asthma } \\
\text { episodes per week }^{\mathrm{e}}\end{array}$} & 2.50 & 2.08 & 0.69 & 2.41 & 2.75 & 2.53 & 0.22 & 0.80 \\
\hline & $(3.37)$ & $(2.55)$ & (1.03) & $(2.47)$ & $(2.41)$ & $(2.95)$ & {$[-0.42-0.85]$} & {$[0.15-1.46]$} \\
\hline & 20 & 18 & 18 & 22 & 21 & 21 & & \\
\hline \multirow{3}{*}{$\begin{array}{l}\text { Number of moderate- } \\
\text { severe episodes per week }\end{array}$} & 1.61 & 0.89 & 0.90 & 1.48 & 1.38 & 1.36 & 0.28 & 0.54 \\
\hline & $(2.08)$ & (1.08) & $(1.70)$ & $(1.40)$ & (1.27) & $(1.23)$ & {$[-0.35-0.90]$} & {$[-0.10-1.18]$} \\
\hline & 22 & 18 & 19 & 22 & 21 & 21 & & \\
\hline \multirow{3}{*}{$\begin{array}{l}\text { Competence with asthma } \\
\text { management (observed) }\end{array}$} & 2.60 & 3.21 & 3.00 & 2.78 & 2.64 & 2.50 & 0.35 & 0.22 \\
\hline & $(1.29)$ & (1.13) & $(1.06)$ & $(1.00)$ & $(1.22)$ & $(1.15)$ & {$[-0.26-0.95]$} & {$[-0.42-0.85]$} \\
\hline & 25 & 19 & 17 & 23 & 22 & 20 & & \\
\hline
\end{tabular}

Abbreviations: T1, time 1 (baseline); T2, time 2 (post-intervention); T3, time 3 (6-month follow-up); Cl, confidence interval.

${ }^{\mathrm{a}}$ Effect sizes (Cohen's $d$ ) represent the T1-T2 change in Intervention group minus the T1-T2 change in Care as Usual group, divided by the pooled T1 standard deviation for the measure. ${ }^{b}$ Asthma Parent Tasks Checklist - Confidence scores (possible range 17-170). ${ }^{\mathrm{C}}$ Asthma Behaviour Checklist - Confidence scores (possible range 22-220). ${ }^{d}$ Asthma Behaviour Checklist - Extent scores (possible range 22-154). ${ }^{e}$ Figures indicate mean number of asthma episodes per week during each 2-week monitoring period. ${ }^{f}$ Figures indicate mean number of days per week where an asthma episode lasted $>2$ hours, interfered with play / school / sleep, or led to shortening of normal activity, seeing a doctor, or going to hospital. ${ }^{\mathrm{g}}$ Possible scores $0-5$. 
Table 4. Means and standard deviations for health-related quality of life outcomes by treatment condition, and effect sizes

\begin{tabular}{|c|c|c|c|c|c|c|c|c|}
\hline & \multicolumn{3}{|c|}{ Intervention $(n=52)$} & \multicolumn{3}{|c|}{ Care as Usual $(n=55)$} & \multicolumn{2}{|c|}{ Effect size $^{\mathrm{a}}$} \\
\hline & $\mathrm{T} 1$ & $\mathrm{~T} 2$ & T3 & T1 & $\mathrm{T} 2$ & T3 & T1-T2 & T1-T3 \\
\hline & $n=51$ & $n=44$ & $n=42$ & $n=55$ & $n=51$ & $n=45$ & & \\
\hline Measure & $\begin{array}{c}M \\
(S D) \\
\end{array}$ & $\begin{array}{c}M \\
(S D)\end{array}$ & $\begin{array}{c}M \\
(S D) \\
\end{array}$ & $\begin{array}{c}M \\
(S D) \\
\end{array}$ & $\begin{array}{c}M \\
(S D) \\
\end{array}$ & $\begin{array}{c}M \\
(S D) \\
\end{array}$ & $\begin{array}{c}d \\
{[95 \% \mathrm{CI}]}\end{array}$ & $\begin{array}{c}d \\
{[95 \% \mathrm{CI}]}\end{array}$ \\
\hline Child HRQL ${ }^{\mathrm{b}}$ & $\begin{array}{c}68.63 \\
(13.85)\end{array}$ & $\begin{array}{c}73.27 \\
(14.94)\end{array}$ & $\begin{array}{c}75.51 \\
(15.56)\end{array}$ & $\begin{array}{c}71.11 \\
(14.56)\end{array}$ & $\begin{array}{c}74.84 \\
(14.99)\end{array}$ & $\begin{array}{c}74.75 \\
(15.36)\end{array}$ & $\begin{array}{c}0.03 \\
{[-0.38-0.43]}\end{array}$ & $\begin{array}{c}0.15 \\
{[-0.27-0.57]}\end{array}$ \\
\hline Parent HRQL ${ }^{c}$ & $\begin{array}{c}59.78 \\
(17.03)\end{array}$ & $\begin{array}{c}67.27 \\
(21.62)\end{array}$ & $\begin{array}{c}70.57 \\
(18.96)\end{array}$ & $\begin{array}{c}63.05 \\
(19.18)\end{array}$ & $\begin{array}{c}65.20 \\
(20.51)\end{array}$ & $\begin{array}{c}63.64 \\
(20.32)\end{array}$ & $\begin{array}{c}0.23 \\
{[-0.17-0.64]}\end{array}$ & $\begin{array}{c}0.57 \\
{[0.14-1.00]}\end{array}$ \\
\hline Family HRQL $^{\mathrm{d}}$ & $\begin{array}{c}53.62 \\
(23.58)\end{array}$ & $\begin{array}{c}62.00 \\
(28.87)\end{array}$ & $\begin{array}{c}65.92 \\
(21.03)\end{array}$ & $\begin{array}{c}61.88 \\
(22.29)\end{array}$ & $\begin{array}{c}66.12 \\
(20.80)\end{array}$ & $\begin{array}{c}62.22 \\
(23.63)\end{array}$ & $\begin{array}{c}0.08 \\
{[-0.32-0.48]}\end{array}$ & $\begin{array}{c}0.53 \\
{[0.11-0.96]}\end{array}$ \\
\hline
\end{tabular}

Abbreviations: T1, time 1 (baseline); T2, time 2 (post-intervention); T3, time 3 (6-month follow-up); Cl, confidence interval. ${ }^{a}$ Effect sizes (Cohen's $d$ ) represent the T1-T2 change in Intervention group minus the T1-T2 change in Care as Usual group, divided by the pooled T1 standard deviation for the measure. ${ }^{b}$ Pediatric Quality of Life Generic Core Scale (possible range 0-

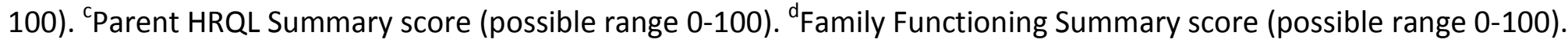


Table 5. Intervention effects for parent and child outcomes by treatment condition

\begin{tabular}{|c|c|c|c|c|c|c|c|c|c|c|c|c|c|c|}
\hline \multirow{4}{*}{$\begin{array}{l}\text { Model } \\
\text { Measure }\end{array}$} & \multirow{3}{*}{\multicolumn{4}{|c|}{$\begin{array}{c}\text { Estimate of fixed effects: } \\
\text { time }^{\mathrm{a}}\end{array}$}} & \multirow{3}{*}{\multicolumn{4}{|c|}{$\begin{array}{c}2 \\
\text { Estimate of fixed effects: } \\
\text { time x condition interaction }^{\mathrm{a}, \mathrm{b}}\end{array}$}} & \multicolumn{4}{|c|}{3} & \multirow{3}{*}{\multicolumn{2}{|c|}{ Comparison $^{\mathrm{c}}$}} \\
\hline & & & & & & & & & \multicolumn{4}{|c|}{$\begin{array}{l}\text { Estimate of fixed effects: } \\
\text { time (separate by condition) }\end{array}$} & & \\
\hline & & & & & & & & & \multicolumn{2}{|c|}{ Intervention } & \multicolumn{2}{|c|}{ Care as Usual } & & \\
\hline & $\beta$ & $F$ & df & $p$ & $\beta$ & $F$ & df & $p$ & $\beta$ & $p$ & $\beta$ & $p$ & $t$ & $p$ \\
\hline \multicolumn{15}{|c|}{ Self-efficacy for illness management ${ }^{\mathrm{d}}$} \\
\hline Eczema & 0.28 & 14.30 & 74.26 & $<.001$ & 0.37 & 7.04 & 73.78 & .010 & 0.48 & $<.001$ & 0.11 & .19 & 2.55 & .01 \\
\hline Asthma & -2.95 & 0.83 & 37.55 & .37 & 3.93 & 0.38 & 36.56 & .54 & -0.69 & .89 & -4.87 & .21 & -0.67 & .50 \\
\hline \multicolumn{15}{|c|}{ Self-efficacy for behaviour management ${ }^{\mathrm{e}}$} \\
\hline Eczema & 10.51 & 19.92 & 81.00 & $<.001$ & 18.04 & 18.28 & 77.96 & $<.001$ & 20.24 & $<.001$ & 2.21 & .45 & -4.31 & $<.001$ \\
\hline Asthma & -2.53 & 0.38 & 42.52 & .54 & 3.06 & 0.14 & 42.47 & .71 & -2.43 & .74 & -4.03 & .46 & -0.18 & .86 \\
\hline \multicolumn{15}{|c|}{ Extent of behaviour difficulties ${ }^{\mathrm{f}}$} \\
\hline Eczema & -9.61 & 42.24 & 150.32 & $<.001$ & -8.93 & 12.16 & 279.33 & .001 & -14.24 & $<.001$ & -5.31 & .005 & 3.50 & $<.001$ \\
\hline Asthma & -2.38 & 3.06 & 85.29 & .08 & -0.23 & 0.01 & 148.92 & .92 & -2.24 & .11 & -1.85 & .32 & 0.17 & .87 \\
\hline \multicolumn{15}{|c|}{ Health-related quality of life ${ }^{\mathrm{g}}$} \\
\hline Child & 2.68 & 16.74 & 90.10 & $<.001$ & 1.02 & 0.60 & 89.94 & .44 & 3.24 & .001 & 2.20 & .02 & 3.24 & .44 \\
\hline Parent & 2.79 & 8.85 & 196.19 & .003 & 4.84 & 6.87 & 195.51 & .009 & 5.33 & $<.001$ & 0.47 & .71 & -2.62 & .01 \\
\hline Family & 2.97 & 6.99 & 192.36 & .009 & 5.78 & 6.83 & 191.42 & .01 & 6.02 & .002 & 0.20 & .87 & -2.58 & .01 \\
\hline \multicolumn{15}{|l|}{ Symptom severity } \\
\hline $\begin{array}{l}\text { Eczema } \\
\text { Asthma }\end{array}$ & -1.49 & 18.17 & 73.61 & $<.001$ & -1.34 & 3.89 & 73.52 & .052 & -2.25 & $<.001$ & -0.89 & .06 & 1.99 & .049 \\
\hline - episodes ${ }^{\mathrm{i}}$ & -0.36 & 2.18 & 76.73 & .14 & -1.02 & 4.79 & 76.69 & .03 & -0.89 & .01 & 0.14 & .68 & -2.01 & .03 \\
\hline - mod-severe & -0.27 & 5.62 & 70.51 & .02 & -0.42 & 3.39 & 70.20 & .07 & -0.49 & .009 & -0.07 & .62 & 1.82 & .08 \\
\hline
\end{tabular}


Competence with illness management (observed)

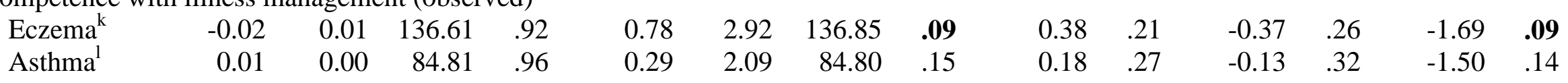

${ }^{a} \beta=$ estimated regression coefficients from mixed-model repeated-measures linear regressions. ${ }^{b}$ Figures indicate the estimated change in the Intervention group from pre-intervention to post-intervention follow-up relative to the Care as Usual group. ${ }^{\mathrm{C}}$ Test of the difference between Intervention and Care as Usual groups for rate of change (estimated regression coefficients); degrees of freedom $=44$ for asthma variables, 81 for eczema variables, 103 for all other variables. ${ }^{d}$ Modified Parental Self-Efficacy with Eczema Care Index (PASECI) (possible range 0-10); Asthma Parent Tasks Checklist - Confidence scores (possible range 17-170). ${ }^{e}$ Eczema Behaviour Checklist - Confidence scores (possible range 25-250); Asthma Behaviour Checklist - Confidence scores (possible range 22-220). ${ }^{\mathrm{f} E c z e m a}$ Behaviour Checklist - Extent scores (possible range 25-175); Asthma Behaviour Checklist - Extent scores (possible range 22-154). ${ }^{\mathrm{g}}$ Pediatric Quality of Life Generic Core Scale (possible range 0-100); Parent HRQL Summary score (possible range 0-100); Family Functioning Summary score (possible range 0-100). ${ }^{\mathrm{h}}$ Patient-Oriented Eczema Measure (possible scores 0-28). ${ }^{\mathrm{i}}$ Figures indicate mean number of asthma episodes per week during each 2-week monitoring period. ${ }^{j}$ Figures indicate mean number of days per week where an asthma episode lasted $>2$ hours, interfered with play / school / sleep, or led to shortening of normal activity, seeing a doctor, or going to hospital. ' $P$ Possible scores 0-11.' Possible scores 0-5. 
Table 6. Intervention effects for symptom severity by treatment group and corticosteroid prescription

\begin{tabular}{|c|c|c|c|c|c|c|c|c|c|c|c|c|c|c|}
\hline \multirow{4}{*}{$\begin{array}{l}\text { Model } \\
\\
\text { Measure } \\
\end{array}$} & \multirow{3}{*}{\multicolumn{4}{|c|}{$\begin{array}{c}1 \\
\begin{array}{c}\text { Estimate of fixed effects: } \\
\text { time }\end{array}\end{array}$}} & \multirow{3}{*}{\multicolumn{4}{|c|}{$\begin{array}{c}\text { Estimate of fixed effects: } \\
\text { time x condition interaction }\end{array}$}} & \multirow{2}{*}{\multicolumn{4}{|c|}{ time (separa }} & \multirow{3}{*}{\multicolumn{2}{|c|}{ Comparison $^{\mathrm{c}}$}} \\
\hline & & & & & & & & & & & & & & \\
\hline & & & & & & & & & \multicolumn{2}{|c|}{ Intervention } & \multicolumn{2}{|c|}{ Care as Usual } & & \\
\hline & $\beta$ & $F$ & df & $p$ & $\beta$ & $F$ & $\mathrm{df}$ & $p$ & $\beta$ & $p$ & $\beta$ & $p$ & $t$ & $p$ \\
\hline \multicolumn{15}{|c|}{ Eczema symptom severity ${ }^{\mathrm{d}}$} \\
\hline $\begin{array}{l}\text { Topical } \\
\text { corticosteroid }\end{array}$ & -1.69 & 16.82 & 53.45 & $<.001$ & -2.43 & 10.01 & 52.76 & .003 & -3.16 & $<.001$ & -0.77 & .14 & 3.18 & .002 \\
\hline $\begin{array}{c}\text { No topical } \\
\text { corticosteroid }\end{array}$ & -1.00 & 2.22 & 44.20 & .14 & 0.70 & 0.27 & 43.94 & .61 & -0.75 & .40 & -1.35 & .20 & -0.44 & .67 \\
\hline \multicolumn{15}{|c|}{ Asthma episodes/week ${ }^{\mathrm{e}}$} \\
\hline Preventer & -0.43 & 1.60 & 51.18 & .21 & -1.54 & 5.64 & 50.63 & .02 & -1.29 & .02 & 0.25 & .56 & 2.38 & .03 \\
\hline No preventer & -0.16 & 0.57 & 22.38 & .46 & -0.05 & 0.01 & 19.51 & .92 & -0.16 & .59 & -0.14 & .69 & 0.05 & .96 \\
\hline \multicolumn{15}{|c|}{ Moderate-severe asthma episodes - days/week ${ }^{\mathrm{f}}$} \\
\hline Preventer & -0.40 & 6.02 & 46.68 & .02 & -0.63 & 4.03 & 46.88 & .051 & -0.75 & .01 & -0.12 & .54 & 1.96 & .06 \\
\hline No preventer & -0.02 & 0.02 & 21.74 & .88 & -0.14 & 0.34 & 19.72 & .56 & -0.07 & .69 & 0.07 & .71 & 0.56 & .58 \\
\hline \multicolumn{15}{|c|}{$\begin{array}{l}{ }^{\mathrm{a}} \beta=\text { estimated regression coefficients from mixed-model repeated-measures linear regressions. }{ }^{b} \text { Figures indicate the estimated change in } \\
\text { the Intervention group from pre-intervention to post-intervention follow-up relative to the Care as Usual group. }{ }^{c} \text { Test of the difference } \\
\text { between Intervention and Care as Usual groups for rate of change (estimated regression coefficients); degrees of freedom: asthma with } \\
\text { preventer }=27 \text {, no preventer }=12 \text {, eczema with topical corticosteroid }=55 \text {, no topical corticosteroids }=22 .{ }^{d} \text { Patient-Oriented Eczema } \\
\text { Measure. }{ }^{~} \text { Mean number of asthma episodes per week during each } 2 \text {-week monitoring period. }{ }^{f} \text { Mean number of days per week where an } \\
\text { asthma episode lasted }>2 \text { hours, interfered with play/school/sleep, or led to shortening of normal activity, seeing a doctor, or going to } \\
\text { hospital. }\end{array}$} \\
\hline
\end{tabular}




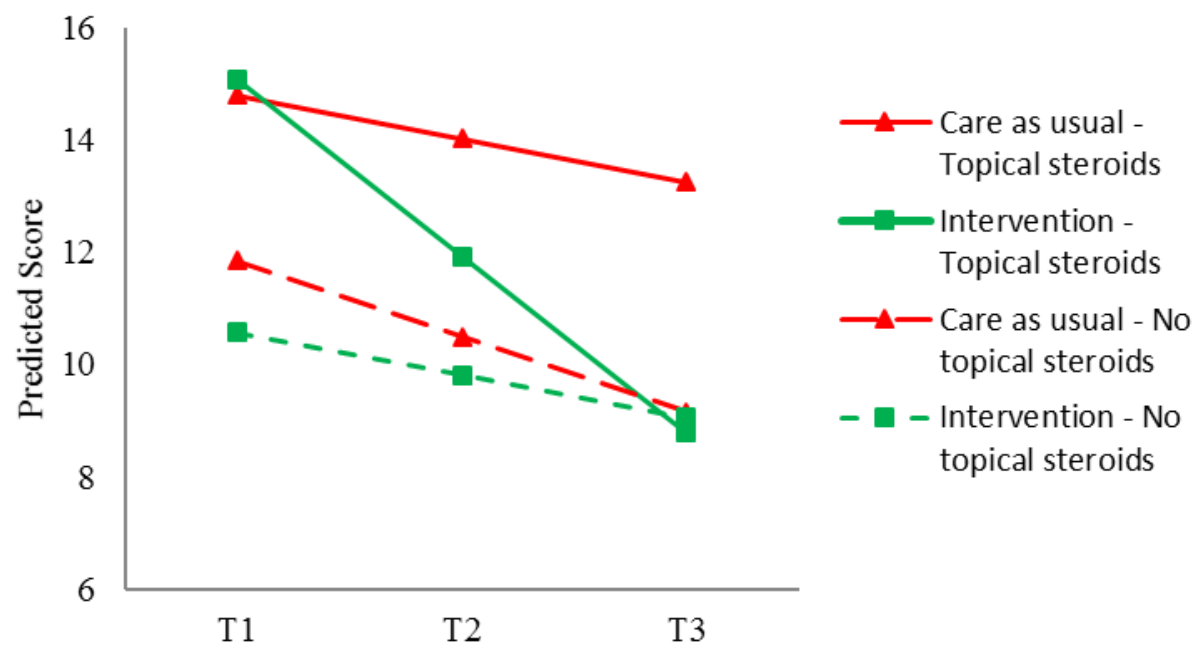

Figure 2. Plots of regression slopes for change over time for eczema severity (mean POEM scores) by treatment group and whether topical steroids were prescribed by the child's doctor. T1 = time 1 (baseline); T2 = time 2 (postintervention); T3 = time 3 (6-month follow-up).

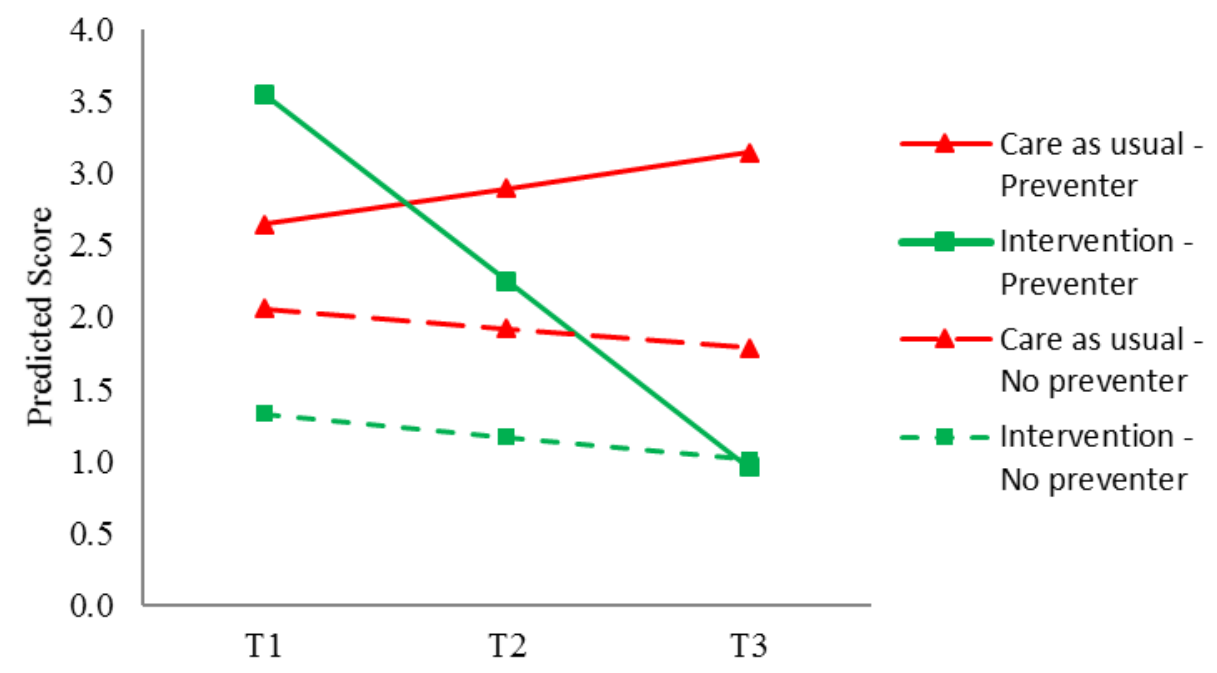

Figure 3. Plots of regression slopes for change over time for episodes of asthma per week by treatment group and whether a preventer was prescribed by the child's doctor. $\mathrm{T} 1=$ time 1 (baseline); $\mathrm{T} 2=$ time 2 (post-intervention); $\mathrm{T} 3=$ time 3 (6-month follow-up). 